\title{
Interaction pattern analysis in cMOOCs based on the connectivist interaction and engagement framework
}

\section{Zhijun Wang, Terry Anderson, Li Chen and Elena Barbera}

Zhijun Wang is an associated professor in the Research Center for Educational Informatization at Jiangnan University. Her research interests includes interaction theory in distance education and connectivism. Terry Anderson is a professor emeritus in the Centre for Distance Education at Athabasca University. His research interests includes interaction in distance education and social networked learning. Li Chen is a professor in the Faculty of Education at the Beijing Normal University. Her research interests includes interaction theory in distance education and lifelong learning. Elena Barbera is a professor in the Psychology and Education department at Open University of Catalonia. Her research interests includes studies in online interaction and learning support and assessment. Address for correspondence: Zhijun Wang, Research Center for Educational Informatization, Jiangnan University, Wuxi, Jiangsu, China. Email: jnuwzj@jiangnan.edu.cn

\begin{abstract}
Connectivist learning is interaction-centered learning. A framework describing interaction and cognitive engagement in connectivist learning was constructed using logical reasoning techniques. The framework and analysis was designed to help researchers and learning designers understand and adapt the characteristics and principles of interaction in connectivist learning contexts. In this study empirical evidence to support and further develop this framework is presented. This study analyzed 6 weeks of data harvested from the daily newsletter, Twitter, and a Facebook group in a wellknown cMOOC led by George Siemens and Stephen Downes. These text transcripts were analyzed using a deductive approach of qualitative content analysis. This study revealed the main activity patterns of participants as they engage in four levels of interaction (operation interaction, wayfinding interaction, sensemaking interaction, and innovation interaction) during the MOOC. Generally the framework serves as a conceptual model to understand and to analyze the interaction in this cMOOC, although some implied interaction is hard to recognize and categorize. The relationship of the four levels of interaction and the role of each element in the framework were explored with the intent of offering the framework as a conceptual and analytic tool to guide both researchers and practitioners in designing and studying connectivist learning.
\end{abstract}

\section{Introduction}

Interaction has always been highly valued in teaching and learning experiences, and especially in distance education (Conrad, 2014). Interaction, primarily between and among learners, but also with content and teacher is essential in cMOOCs, which are designed using connectivist pedagogical ideas. The pedagogical structure in cMOOCs is a by-product of the interactions with all participants and with content (Siemens, 2013). Interaction both with other humans and with network resources are critical functions in connection building, network formulation and knowledge creation and generation. These attributes distinguish cMOOCs from traditional courses developed using cognitive-behavioral and social constructivist pedagogies (Anderson \& Dron, 2011). Interactions in cMOOCs are distributed and multispaced (Siemens, 2013) as compared with traditional courses offered either in classrooms or online. In traditional courses, interaction 


\section{Practitioner Notes}

What is already known about this topic

- Connectivism is a new learning theory grounded in and developed within a digital age.

- cMOOCs are a form of MOOCs based upon connectivism pedagogy that use interaction centered learning in complex information environments.

- A framework modeling interaction and cognitive engagement in connectivist learning context was developed (Wang, Chen, \& Anderson, 2014). The Framework divides interactions in connectivist learning into four levels according to the cognitive engagement and challenge to the learners: operation interaction, wayfinding interaction, sensemaking interaction, and innovation interaction.

What this article adds

- The main interaction patterns in each level of interaction are described in the study. The model gives a clear explanation of how learners interact with each other in cMOOCs.

- The framework was validated through interaction analysis in a real connectivist learning context.

- This study developed the framework further by extracting and describing the specific interaction method learners used in their learning. It also clarified the relationships of the four levels of interaction and the relationship of elements in each level of interaction and cognitive engagement.

Implications for practice and/or policy

- This study will help researchers and practitioners develop a clearer understanding of how connectivist learning happens from an interaction perspective, which can enhance the design and effectiveness of cMOOCs.

- The interaction patterns and method of learning explored in this study can be used in other connectivist learning contexts to facilitate or research effective learning.

is always centered in a specific classrooms, discussion forums, blog sites, or other spaces established for learners. By contrast, cMOOCs are primarily centered on a course web page and as the course goes on, interactions can occur or emerge in many spaces, including blogs, wikis, Twitter, Facebook, Google Groups, Second Life, YouTube, and dozens of others. Wang, Chen, and Anderson (2014) noted that interaction in these connectivist learning spaces is often complex and deserves extra attention.

\section{Related work}

The development and innovation of cMOOCs and the importance of interaction

Connectivism, which was proposed as a "learning theory for the digital age" (Siemens, 2005a), has attracted researchers' attention as it provides a fresh perspective on learning and teaching as it occurs in an age of pervasive Web2.0 and social media use. Learning is viewed as a process of developing networks and connections among people, information, and digital learning artifacts within a ubiquitous network. Two early developers of connectivism, George Siemens and Stephen Downes, led a team of connectivist learning researchers in developing and running a series of Massive Open Online Courses to test and develop their ideas of Connectivism in real life contexts (Siemens, 2011) 
between 2008 and 2014. These included MOOCs titled CC08, CCK10, CCK11, Change 11MOOC, Openness in Education, etmooc, REL2014 (Wang, Chen, \& Zhen, 2014). MOOCs were later developed and delivered by traditional universities however they most often were based upon cognitivebehavioral pedagogies. The Siemens and Downes style MOOCs have become known as cMOOCs to emphasize their connectivist pedagogy. These connectivist cMOOCs are distinguished from the more expository pedagogies used in what Downes (2012a) coined as xMOOCs. The two pedagogical approaches to MOOCs are quite different (Yuan, Powell, \& Cetis, 2013) and thus demand different means of assessing outcomes. Siemens described this difference. "Our MOOC model emphasizes creation, creativity, autonomy, and social networked learning. The Coursera model emphasizes a more traditional learning approach through video presentations and short quizzes and testing. Put another way, cMOOCs focus on knowledge creation and generation whereas xMOOCs focus on knowledge duplication" (Siemens, 2012). MOOCs have been discussed and debated intensively in the past 4 years; however, most attention has been focused on the so called xMOOCs, which followed a linear instructor-led approach, rather than as in cMOOCs in which participants are cocreators - charged with self-organizing their learning. The center of cMOOCs is interaction and network creation, especially, learner-learner interaction focused on learners' networked knowledge creation and growth (Downes, 2012b, p. 63; Siemens, 2011, p. 85).

Many researchers and learners who are interested in connectivism have experience as participants in MOOCs learning using this relatively new pedagogy. Other researchers have worked with the introduction of change and innovation associated with this new model of learning from both the course design and technology perspectives. For example, Garcia, Brown, and Dungay (2014) and Rodriguez (2013) introduced the "blog delivery model of connectivist learning" and "delivery model of cMOOCs" respectively. Fini (2009) described the technological dimension of MOOCs, and Kop and Carroll (2010) and Fournier, Kop, and Durand (2011) focused on the design and construction of Personal Learning Environments using these distributed technologies in the context of cMOOCs. Other researchers were interested in learners' learning and participation experience. For example, Saadatmand and Kumpulainen (2014) introduced the participants' perceptions of learning and networking, Smith and Eng (2013) compared student experience of cMOOCs and xMOOCs; Levy (2011) summarized the lessons learned from participating in MOOCs; Kop and Carroll (2011) examined the challenges to learners associated with connectivist models. A few researchers have focused on the facilitators or teachers experience (Arnold, Kumar, Thillosen, \& Ebner, 2014). Only two researches (Milligan, Littlejohn, \& Margaryan, 2013; Siemens, 2011) have described the patterns of interaction and communication used in connectivist learning environments - specifically cMOOCs. However, in Milligan's research, the number of participants interviewed is limited compared with the massive number of learners. Siemens' doctoral research focused on the learner orientation in complex online learning environments and he only analyzed the data generated in a single CCK 08 forum (Siemens, 2011, p. 87). By contrast earlier online education researchers typically analyzed interaction in the threaded forum discussions where data is well structured and they rarely or never analyzed unstructured data generated in a distributed and multitechnology based environment during the learning process. Fournier stated that cMOOCs have large, incomplete, and dispersed data sets (Fournier et al, 2014) which present numerous challenges to researchers, yet the interaction that occurs in these distributed environments may be critical and possibly deeper than forum discussion in cMOOCs. Little attention and study has been paid to this challenging context and especially using empirical methodologies. Thus, we hope our contribution and analysis of the interaction patterns in this distributed learning environment is both timely and relatively unique.

There are three widely used interaction analysis frameworks that have been developed to study interactions in traditional online learning environment (Henri, 1992; Gunawardena, Lowe, \& 
Anderson, 1997; Garrison, Anderson, \& Archer, 2001). Henri's model is "a teacher-centered instructional paradigm" (Gunawardena et al, 1997), Gunawardena et al's model is focused on social construction of knowledge while Garrison et al's framework focus on the three phases of the Community of Inquiry Model—social, teaching, and cognitive presence. Distance education pedagogy has evolved from exclusive cognitive-behavior pedagogies to support both social constructivist and connectivist pedagogies (see Anderson \& Dron, 2011). All frameworks mentioned above are associated with either behavior-cognitive or social constructive pedagogies that focus on knowledge transmission and construction in group-based learning designs. However, connectivist pedagogy emphasizes knowledge creation and generation of collective knowledge within distributed social networks. Since there is significant difference between these pedagogies and the contexts in which they evolved, a new framework was developed with the intent of identifying and quantifying the characteristics of connectivist learning models. We built such a framework (Wang, Chen, \& Anderson, 2014; Wang \& Chen, 2015) to reveal the characteristics and principles of interaction in connectivist learning environment from a systematic perspective, which we describe next.

\section{Connectivist interaction engagement framework}

In order to study and reveal the characteristics and principles of interaction in connectivist learning, Connectivist Interaction Engagement (CIE) framework was developed by combining the Hierarchical Model for Instructional Interaction (HMII) (Chen, 2004a, b) in distance learning and Bloom's revised taxonomy (Anderson et al, 2000) with Siemens' elements of wayfinding and sensemaking (Siemens, 2011). We used a theory building methodology for this analysis and framework construction (Wang, Chen, \& Anderson, 2014). HMII divides the interaction in distance education into three levels based on Laurillard's (2000) conversation framework that includes operation interaction, information interaction, and concept interaction that range from concrete to abstract and from low to high levels. After a systematical review of interaction research especially framework construction in distance and online education, we found the HMII, revealed the basic interaction principles of distance and online learning (Wang, 2011), thus, it was selected as a launching platform for the interaction framework. All three levels of interaction in HMII were reanalyzed. The operation interaction was developed from literature on interaction in Web 2.0 and social media environments. Information interaction was further divided into wayfinding interaction and sensemaking interaction according to Siemens' discussion of learning in complex online learning environments. Finally, concept interaction was changed into innovation interaction as it is the most critical level for achievement of learning objectives. Then, these new four levels of interaction were analyzed and compared using Bloom's revised taxonomy to help us to understand the levels of cognitive engagement. After this concept framework building and mapping to interactions in the transcripts, the CIE framework was built. The Framework shows interaction in connectivist learning divided into four levels according to the level of cognitive engagement and challenge to learners (see Figure 1). It progresses from operation interaction, to wayfinding interaction, sensemaking interaction, and finally to innovation interaction. Learners use these interactions to support their learning. They build interaction spaces (personal learning environments) with different technologies to connect with knowledge and networking opportunities through operation interaction in support of their learning. Wayfinding interaction is used to connect the pipelines for knowledge flow (Siemens, 2011, p. 79) including the connection of information and people interacting in groups, sets, or networks as described by Dron and Anderson (2014). Sensemaking interaction is pattern recognition and information (knowledge) seeking in a collaborative process which includes information aggregation/sharing, discussion/negotiation, reflection, and decision making. Innovation interaction is the most challenging and critical interaction for learners and from this interaction artifact are created, 


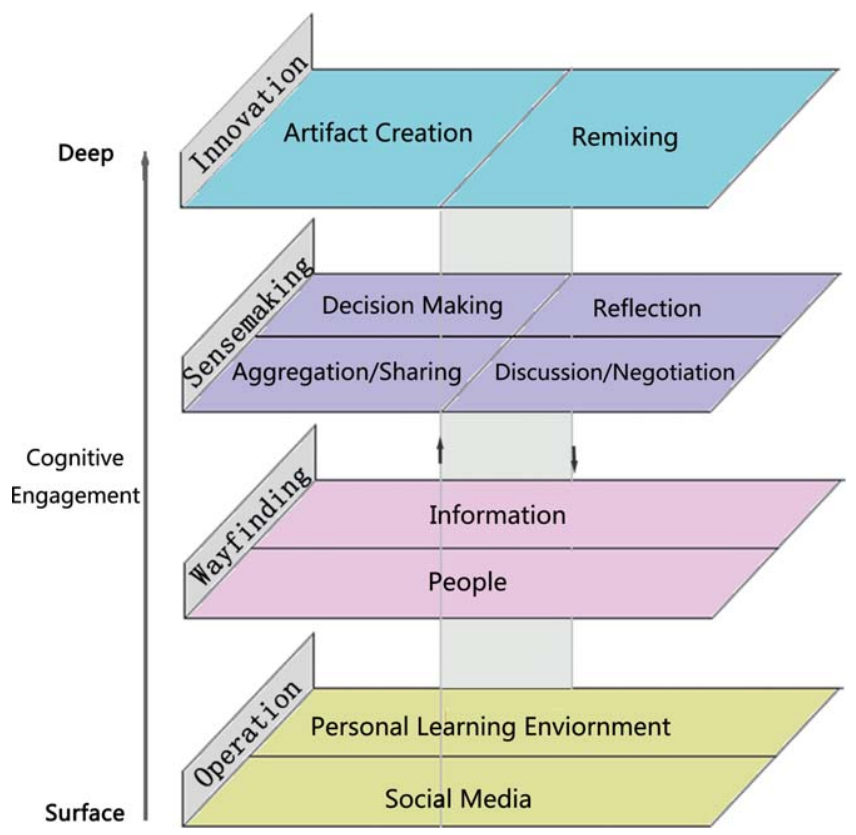

Figure 1: Connectivist Interaction and Engagement (CIE) Framework from Wang, Chen, \& Anderson, 2014

remixed, shared, and commented upon. These four levels of interaction work together as a circulating, transactional, and networked process with significant recursion.

This framework described interaction in connectivist learning from the perspective of a systematic development based upon educational interaction literature and theory. However, more research to support and develop it needs to be done from an empirical perspective.

\section{Research questions}

This study aims to develop the CIE framework further based upon empirical data generated from the interaction of learners in a cMOOC distributed learning environment. The study was designed to describe and categorize participant interaction functions and patterns in a real connectivist learning context. The research questions are therefore: (1) Does the interaction that happens in this cMOOC match with the CIE framework theorized in connectivist learning?; (2) What is the relationship among the four levels of interaction in the framework in cMOOCs?

As noted earlier, research of interaction in cMOOCs is challenging due to the complex and distributed characteristics of this kind of learning. This study is done with the hope that it may provide an example using the CIE framework to identify interaction pattern in connectivist learning environment.

\section{Methodology}

Course selection

Change 11 was an early MOOC that attracted worldwide attention from researchers and learners in educational technology and distance education (2011). It was co-facilitated by Dave Cormier, George Siemens and Stephen Downes in 2011. The cMOOC was unusual in that it lasted for 36 weeks (from September 10, 2011 to May 28, 2012) which was much longer than previous MOOCs. While this cMOOC was running, the term "MOOC" began to be well known by people 


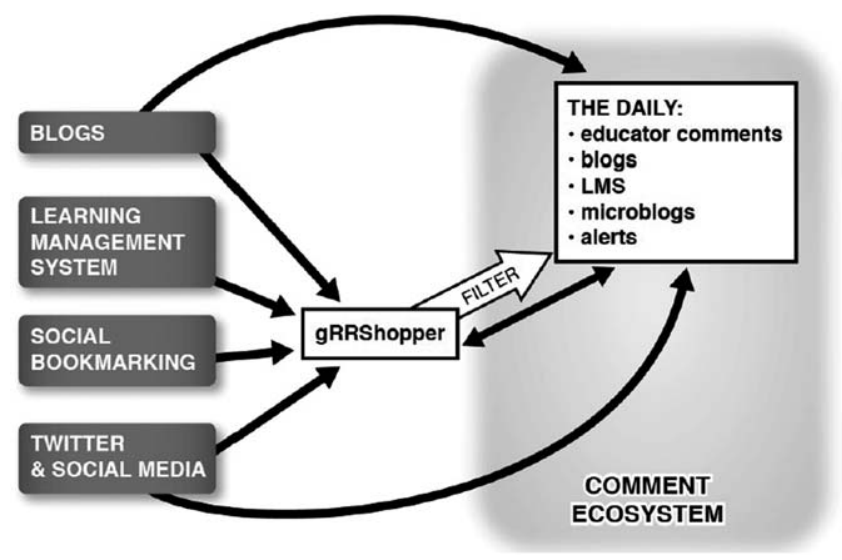

Figure 2: Structure of daily newsletter

around the world. This course was referred to as the "Mother of all MOOCs" by some participants - partially due to its length but also to the attention focused on it by many early adopters and researchers associated with online learning. It is a typical and in some sense archetypical cMOOC which warrants further research and analysis. Thus, Change 11 MOOC was selected as the data source for this study.

Data collection and analysis

Change 11 MOOC was designed to introduce and encourage interaction with major contributions made by researchers in the field of instructional technology. Each week, an invited professor (or researcher) joined the course and participated using both synchronous and asynchronous web based technologies. As other cMOOCs, learners made active contribution via different Web2.0 technologies and digital platforms in the process of course learning activities. All their contributions distributed in the discussion, blog entries, etc. were aggregated using a tool called gRRShopper (see Figure 2). gRRShopper attempts to harvest all resources related to the course that are distributed over the internet and that include a special tag defined by facilitators and used by all participants - in this case "\#change11". A daily newsletter distributed the collection of distributed content created by learners in the course. These aggregated contents were distributed to all participants using email, RSS, and on the course website. Participants received detailed information distributed in different spaces by accessing the URL, following the \#change 11 hashtag or reading the gRRShopper posts. This study collected data from the daily newsletter and by tracking the interaction flows distributed across the network.

The course lasted 36 weeks and more than 2000 people interacted in many different spaces thus it is impossible to comprehensively analyze all data generated in the course. However, analysis of the most intensive interaction data can help us gain a deeper understand of how learners interact with each other in such connectivist learning contexts. This study counted the number of topics generated in the interaction spaces (see Figure 3). Except week 1 to week 6, the number of topics decreased with some fluctuation as the time progressed from week 7 to week 36-likely due to participant fatigue as this long course evolved. This study chose week 1 to week 6's data for further data tracking and analysis as this was the most active portion of the cMOOCs.

We identified four categories of data in Change 11 MOOC from week1 to week 6 including the number of registrants, daily newsletter subscriptions, and the number of personal blog feeds linked to the course (see Table 1). At the beginning of the course, more than 1300 peoples had registered, and almost everyone subscribed to the daily newsletter. The number of participants 


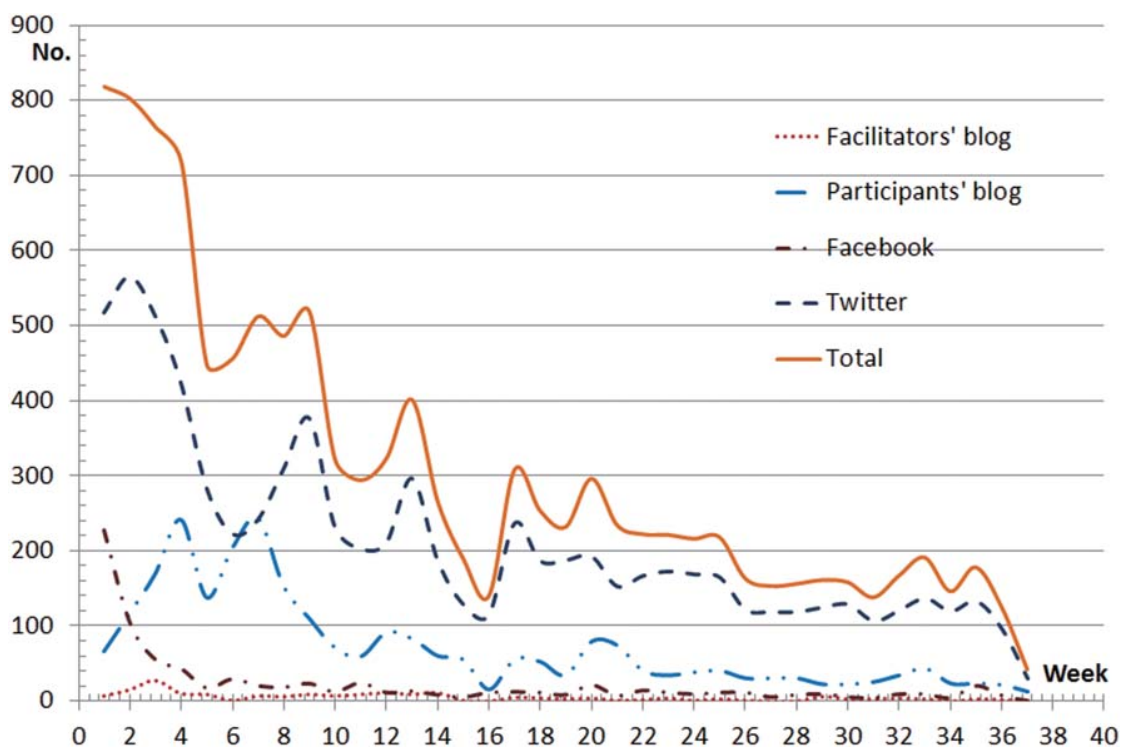

Figure 3: Statistics of post number in Change 11 MOOC

increased over this 6-week period. By the sixth week, more than 2000 people had registered for the course.

To ensure that all data was collected consistently the following three data collection rules were defined: (1) Following the URL of the topic in each week's daily newsletter to track the interaction based on a specific topic. The interaction based on the blog is not a linear process because participants usually connect it with other blogs, topic and resources; all of them should be tracked until all this data is collected. (2) All data related with a specific topic is collected until the end of the topic, no matter how many weeks the interaction lasted (some topics lasted for 3 weeks). (3) Delete all duplicated data when the data collection process has ended.

Research method

The deductive approach of qualitative content analysis is useful when the aim is to test a previous theory in a different context (Elo \& Kyngas, 2008). In this study we used the CIE framework to identify and categorize the interaction pattern of learners. An unconstrained categorization matrix was developed within the guiding theoretical model of the Framework, so new categories were added during the coding process. In content analysis different units of analysis might be used to focus on different phenomena or data within the same study (Rourke, Anderson,

Table 1: Statistic information of Change 11 MOOC

\begin{tabular}{lcccccc}
\hline & Week 1 & Week 2 & Week 3 & Week 4 & Week 5 & Week 6 \\
& $9.10-9.16$ & $9.17-9.23$ & $9.24-9.30$ & $10.1-10.7$ & $10.8-10.15$ & $10.16-10.22$ \\
\hline $\begin{array}{l}\text { Registered } \\
\text { Subscribed } \\
\text { to Daily } \\
\begin{array}{c}\text { Newsletter } \\
\text { Blog feed }\end{array}\end{array}$ & $1370-1774$ & $1805-1892$ & $1912-1940$ & $1966-2013$ & $2018-2079$ & $2092-2130$ \\
\hline
\end{tabular}


Garrison, \& Archer, 2011). For the data collected from the distributed blog post, Twitter and Facebook group were different; and we used different coding units in different spaces. In the blog posts the coding units were divided by meanings while in Twitter we treat the message as one coding unit. All data were reviewed and coded correspondence with or exemplification of the categories (Elo \& Kyngas, 2008) focusing on participants' interaction patterns from the method perspective. Two research assistants and the first author of this article were involved in the coding process. To ensure the research trustworthiness, the first author and one professional research assistant coded the first 2-week's data separately with Nvivo8.0 and then the emergent coding book was shared and discussed to get consistent understanding. Finally, the researchers recoded all data again to achieve the same rules for of coding and then coding all data collected until we found that no new interaction methods and patterns were emerging (data saturation). The coding book was saturated after we coded the fifth week's data in this study.

\section{Findings}

Research question 1: Does the interaction that happens in this cMOOC match with the CIE framework theorized for connectivist learning?.

Table 2 presents the themes as they evolved through the phases of a deductive approach to qualitative content analysis coding and finally as theorized by the CIE framework.

Sharma, Jordan, Swain, and Smith (2010) identified six patterns of discourse in online communities. In this study, we found the interaction in cMOOCs is more complex and diverse than in other learning contexts.

Operation interaction

Operation interaction occurred during the cMOOCs learning process at all times. However, it tends to leave no traces when learners actually interact with the platform or media interface, thus it is hard to identify the operation interaction patterns by content analysis. We speculate that two operation interaction patterns were occurring.

1. Setting and testing the environment as identified by the visible content left directly on the internet. When learners start to set their own learning environment with different social media, they often send a test post to check whether the environment is working or not, such as a participant posting a blog "testing the tag to see if it works \#change11" to test the tag in aggregation system.

2. Provision of operation guidance. This is a pattern related to both operation interaction and wayfinding interaction. Operation guidance of particular learning environments was provided to help learners build and enhance their own learning environment, such as "Downes" post "setting up your social web" guide learners building their personal learning environment with step by step instructions.

Wayfinding interaction

Connecting with information and with people are two types of wayfinding in CIE framework for learners. In a similar manner to operation interaction, connecting with information is difficult to recognize through content analysis as the traces (ie, web logs, time spent reading articles, etc.) are usually not available for study by researchers or as basis for collaboration by other learners. The wayfinding interaction patterns described in the coding book are all about connecting with people. They were divided into four patterns, including help others wayfinding, active and direct wayfinding, participatory but indirect wayfinding and other kind of wayfinding. Helping others wayfinding occurs when learners assist others to participate in the course by providing strategy guidance, sharing sites to facilitate them participating in the course, such as providing wayfinding strategy guidance, sharing sites, and activation. Active direct wayfinding occurs when leaners connect with resources and build social networks by introducing and recommending the 
Table 2: Coding book of interaction patterns in connectivist learning

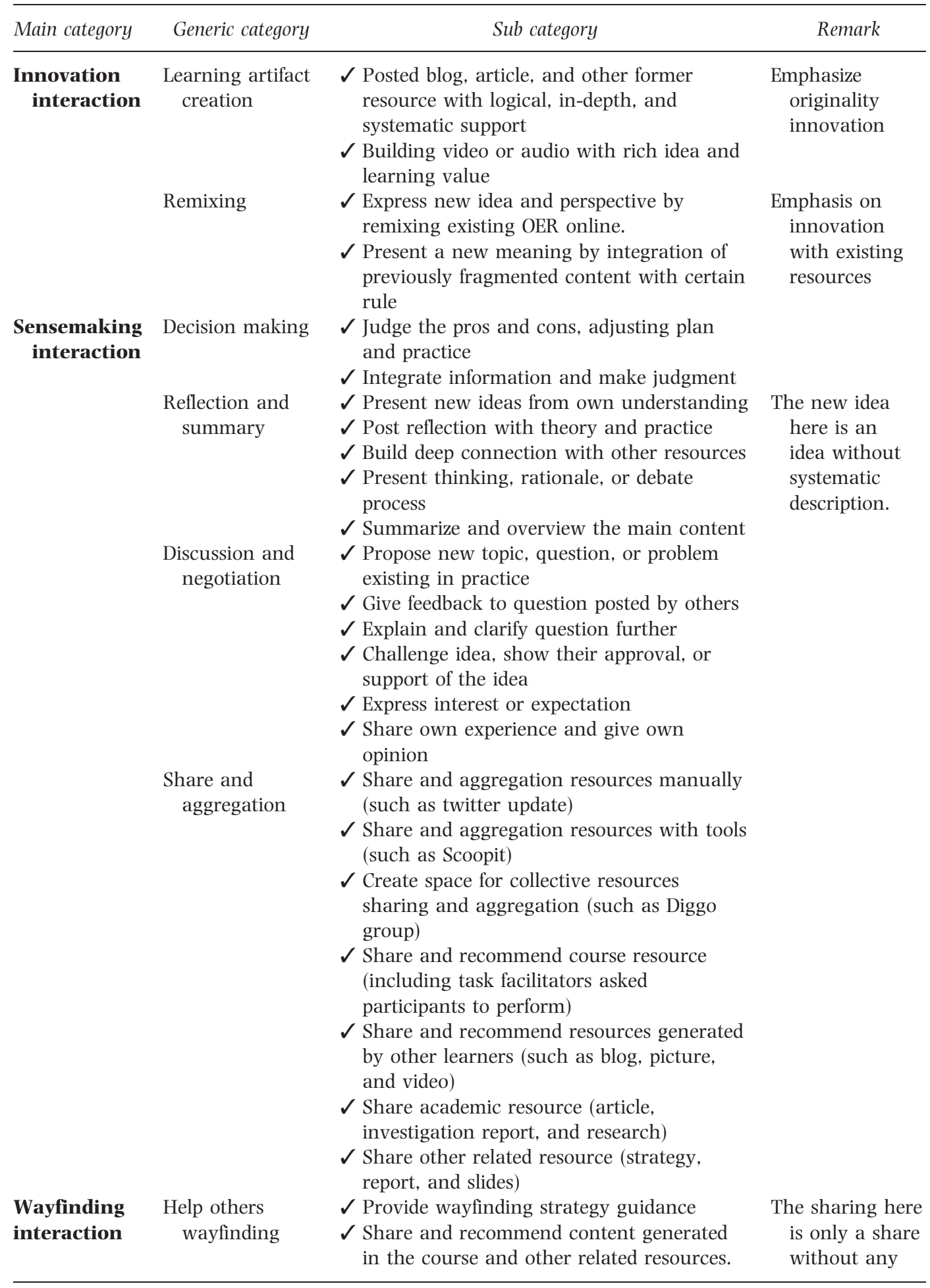


Table 2: Continued

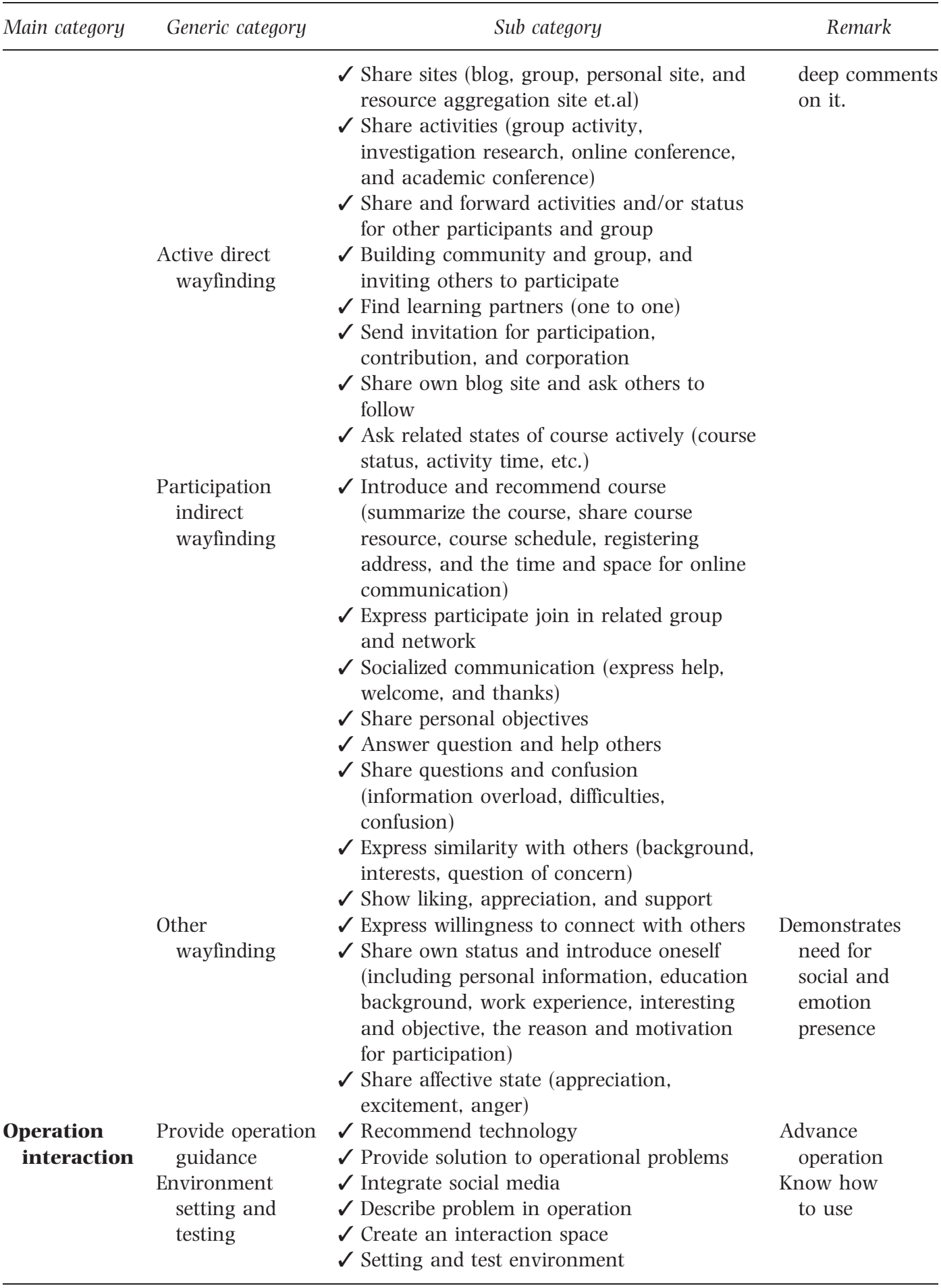


course, building group, organization and activities, and inviting others to join in. Five groups were built by participants during week 1. Participatory indirect wayfinding occurs when learners participate in activities and join in existing networks to build their own social networks and help themselves to wayfind. These include sharing their affective states and emotions, revealing their participation activities and many other ways listed on the coding book. Other kind of wayfinding is referring to the behavior demonstrating their need for social and emotion presence which is hard to category to the former three kind of wayfinding.

\section{Sensemaking interaction}

We discerned four kinds of sensemaking interaction in the CIE framework: resources aggregation and sharing, discussion and negotiation, reflection, and decision making. All this patterns were recognized in the MOOC transcripts.

1. Sharing and aggregation: There are many ways to aggregate resources in this course, such as building groups with Diggo, and use of curation tools or just building web sites. Most of the tools used for resources aggregation were open tools found on the net. Resource aggregation and sharing nearly always occurred at the same time. Such as "Paulo Simões" use Change11 | Scoop.it to aggregate and share useful and valuable resources mentioned or shared by other participant. Learners also built Diggo Groups to aggregation and share resources from week 3.

2. Discussion and negotiation: They are not only found in course forums, but are also the content of blogs, Facebook posts, Twitters, and are especially noticed when a learner presents their thinking and debating process in their blog and the post generates responses. An example of this occurred in the post "Where does a MOOC begin life?," "Apostolos K" summarized how this question was posted; who made what kind of contribution to help him establish this new idea and what are his views on this issue. There were three ways that were used extensively to post one's ideas in Change 11 MOOC including blog post presenting their learning and debating processes and their own ideas; replying to others' blog often providing examples or arguments to explain and support their idea; distributing their response or attitude, such as publically agreeing or disagreeing.

3. Reflection: Reflection provides important evidence of in-depth thinking as revealed by reflective posts on ideas encountered in the learning process. For example participant "bioram" posted "Reflections on a connectivist model and MOOCs \#change11" and "Personal Reflection on Online Learning and MOOCs \#change11. Overview and summary presentations were typical reflection strategies used. Though no new ideas were generated in these summaries, they can help other learners to connect with the state of the course or catch up with missed activities in a short time. For example, "Luis Rafael Amario" published a post "Change11 ready to share learnings and change in education \& technology!" which introduced the course synoptically with his own learning process.

4. Decision making: Decision making is also an implicit process rarely leaving data online. We can only sense this process by "reading between the lines" of content posted by participants. When participating in the connectivist courses, learners have to judge the filter and value the often large doses of information that they receive and adjust plan and practice contributing themselves from time to time. These include decisions related to how to learn, who to interact with, what kind of interaction group to join, whether to post their idea or not, and so on. Although compared with the larger decision making process in complex learning environment, they are small ones, all of them are decision making process that taken together help match the course with learners' time, experience, interests, working, and learning needs. 


\section{Innovation interaction}

There are two kind of innovation interaction in our framework. Learning artifact creation focuses on original innovation, while remixing focuses on innovation using existing resources. Compared with new idea creation in sensemaking interaction, the learning artifact created and remixing here emphasize the expression of new ideas systematically and logically, as the artifact is constructed. There were four innovation interaction learners used most often in this course. (1) Posting of blogs, articles, and other resources with logical, in-depth, and systematic exposition of an idea. (2) Building video or audio artifacts with rich idea and learning value. (3) Expressing new ideas and perspectives by remixing existing online Open Education Resources (OER). (4) Presenting a new meaning by integrating small resources using certain rules to create a new object.

From this research we find that interaction in this cMOOC generally matched with the CIE framework, however, some implicit interaction patterns are rarely recorded and shared on the internet; thus, we are left inferring their existence. Generally the ICE framework served as a usual conceptual model that provides a heuristic to both understand and to analyze the interaction in this cMOOC.

Research question 2: What is the relationship among the four levels of interaction in the framework in cMOOCs?

In our previous research, it was proposed that the relationship among the four levels of interaction is a networked process with significant recursion. The lower levels of interaction are the foundations of the higher and each level influences the next. The development of higher levels assumes learning at lower levels (Wang, Chen, \& Anderson, 2014; Wang \& Chen, 2015). This kind of relationship is much clearer in this research.

Learners in this cMOOC needed to learn how to use different social network technologies to establish and maintain their personal network environment. This learning includes activities such as setting environmental parameters, building blog, and twitter accounts, following RSS feeds and using Open ID so that they can both access and contribute using various platforms and spaces to build their personal networks and develop their online learning identity. This operational interaction was rarely recorded directly, if they cannot operate these technologies it is difficult or impossible for them to participate in the course. That is why two facilitators of the course, George Siemens and Stephen Downes, provided a great deal of information about how to participate in this type of MOOC learning and guidelines for establishing the learning environment in the first week of the course. One can assume that as individuals and society as a whole gains expertise and "net literacy" that the need for such tutorial intervention by instructors will decrease. There were some problems with the synchronous video conferencing technology used from the second week to the forth week in the Change $11 \mathrm{MOOC}$, so the course did not progress as anticipated. This resulted in a negative learning experience for many learners. Thus, operation interaction can influence the other three kinds of interactions directly in online learning environments and at least minimal levels can be seen as both a foundation and a prerequisite to further learning.

During the first week of the course, most learners search to find other learners and participants in the course in these networked spaces using strategies listed in Table 2. They also construct their learning spaces and environment, such as self-introduction, sharing the URLs of their owned online spaces, and blog sites. They also typically share their feelings, learning objectives and strategies, and call for participation in the networked space that they build. From here they begin to share course content, reflections, questions and other information, and resources related to the course. In other words, with wayfinding interaction, learners build a surface connection with people and with information first. It is an important prerequisite for learners to participant in 
further deep interaction and learning. They connect with people first, because everyone can be a filter, a sharing device, an extractor, and an aggregator of information-thus, amplifying one's capacity to connect with is limited only by available personal skill, time, and energy.

The rapid development of social media and network technologies enhance filtration, identification, selection, and integration of information, so that learners can benefit from more highly qualified information and connect with more efficiency. New questions, ideas, and insights may be inspired by their interaction and communication with high quality information sites and smart people with whom they connect during wayfinding interaction. Thus, wayfinding serves as an essential prerequisite for sensemaking interaction and innovation interaction.

Sensemaking interaction is the implicit act of connection building and idea formation. It further refines and optimizes existing connections among information and people and in the process generates new wayfinding interaction needs and ideas, so as to operationalize interaction needs. In Change 11 MOOC, learners build Facebook groups in both English and Spanish discussions and sharing of profiles and interests, and they build a Diggo group for wider information sharing and aggregation. Although the first week of Change 11 MOOC is an orientation week to help learners build their own learning environment with social media and setting own learning object, some "senior" MOOC learners posted their reflections on some topics which attracted deeper interactions that reached the innovation level. With information sharing and aggregation, deep discussion and negotiation, reflection and decision making in blog post, diverse viewpoints were gathered and implicitly evaluated for relevance as they contribute to individuals' growing knowledge constructs. We found some evidence (mostly from self-reflections) that learners generally understand the connection of information and meaning and often gained a new understanding of problems in this process. New ideas were generated in this process as a foundation for innovation interaction.

Innovation interaction is the most challenging one to learners of the four level of interaction, and only a few of participants reached this level as evidenced by their posts. However, when this type of post or learning artifact was generated, it often spun off a series of deep discussions and reflections and even led to the generation of new learning artifacts. These topics acted as the so-called "obligatory passage point (OPP)" in Actor Network Theory (Fenwick \& Edwards, 2010) for learners. For example, Glenyan's "The C stands for Conference-MOOC" posts his thinking about what a MOOC is and how it can be applied to language learning. It attracted participants' attention and inspired deep discussion as comments on the post and in others' blogs. Further, much information and resources related to this post were shared among participants. Innovation interaction is critical for connectivist learning. Learners express their thoughts and ideas deeply, systematically, logically, and creatively, so as to build deeper connections promoting their own and their peers' connectivist learning.

The interaction in Change 11 MOOC was a complex process. At the beginning of the course there seems to be a more or less lineal process among the four levels of interaction; however, after the first week of the course, this process became quite complex. Operation interaction happened throughout the course, and the other three kind of interaction happened according to learners' needs, abilities, and responses. We found that although thousands of posts and comments were generated, most of them belonged to sensemaking interaction, and only of few of them reached the innovation interaction level. This may mean that, although thousands of learners participated in the course, only a few of them showed evidence of reaching innovation interaction levels. In other words, the higher the interaction level the more challenging are the technical and time requirements; thus, fewer participants reached these higher levels of interaction. This study also found that the boundaries among the four levels of interaction were not absolute - there was some overlap between the adjacent levels. For example, the information sharing existed in both 
wayfinding and sensemaking interaction and new idea presentation existed in both sensemaking and innovation interaction in Table 2. The cognitive engagement of learners was used here to as criterion to distinguish between them. When participants share information without any deep comment or analysis, sharing belongs to the wayfinding interaction levels rather than to the sensemaking level.

\section{Discussion}

This cMOOC was developed and ran in 2011. The data we studied was left as text and audio recordings which still exist openly on the Internet. However much operational interaction is more private and likely has disappeared in the learning process. It is challenging to view and analyze interaction patterns of operation interaction and connecting with information as wayfinding in the study. However, the operation interaction which focuses on human-computer and human interface interaction has been researched for a long time in both educational technology and computer science areas (Chen, 2004b). These operation interaction patterns remain useful in Web2.0 and social media environments, which are the main technology used to support connectivist learning. Learners connect with information using the help of search engines and more personal technologies especially semantic technologies, such as tags, recommendations, and correlation tools. Learners can also established personal resource sites or use existing filtering and curation technologies to both select and aggregate information as Scoop.it and the recent announcement of Google Collections.

Cognitive engagement is an important element in the CIE framework. The possible relationships among cognitive engagement and each level of interaction were proposed in a previous study (Wang, Chen, \& Anderson, 2014; Wang \& Chen, 2015). The level of cognitive engagement was considered in this research when building the coding book for interaction patterns, and especially for the overlap ones between adjacent levels. However, further research should be done to identify and differentiate the existence and role of cognitive engagement in each interaction patterns.

The claim that "learning is connection building and network creation" (Siemens, 2005a) is the most famous statement of connectivism. In the development of this learning theory, most research to date has gleamed only a surface understanding of the complex cognitive and social processes that constitute learning (Bi \& Yang, 2014; Wang, 2011). When comparing the interaction patterns with the claims about connectivism, most interactions happen at only wayfinding interaction. Many seem to fail to gain deep understanding of complex topics which are claimed for connectivist learning. We propose that only if the connection and network building contains all four kinds of interaction and especially innovation interaction, can we state that there is evidence of connectivist learning taking place.

It is interesting to note that most wayfinding interaction patterns and methods were found in the interaction content of Twitter, while most sensemaking interaction and innovation interaction patterns and methods were found in the blog posting that we tracked through the daily newsletter. This is likely due to the limitation of 140 characters in Twitter, but also the ease with which sensemaking discoveries can be distributed quickly using Twitter. In the Facebook group instances of all forms of interactions can be found, but much less than Twitter and blog supported interaction. Thus, it is likely that the affordances of each application match with and support different functions at different levels in the framework.

\section{Conclusions and future work}

This study analyzed the interaction data obtained by tracking 6 weeks' daily newsletter data, Twitter, and Facebook group in a pioneering cMOOC — Change 11. Using deductive content analysis, a coding book of interaction in connectivist learning was built to analysis the interaction patterns and methods learners used in each level of interaction, and further clarified the 
relationship among the four levels of interaction. These contributions to the course provided many clear explains of learner interaction in cMOOCs. What is more, this study found that generally the framework served as a usual conceptual model that provides a heuristic to understand and to analyze the interaction in this cMOOC.

Our next step in this line of research is to use this coding system to analysis the interaction method week by week in different interaction spaces used for instruction or learning such as blogs, Twitter, Facebook, video conference, etc., to find the interaction methods and patterns learners used most often in these spaces. Further we hope to use the framework to describe and measure the change process within the course so as to gather more detailed characteristics and principles of each level of interaction in CIE framework, and the role of cognitive engagement in each interaction pattern. Learning is a process of connection and network formulation (Siemens, 2005b). The network includes not only social networks, but also technology and conceptual networks. More research is needed not only on each of these individually and in concert, but also how these networks influence all four kinds of interaction processes as well.

We note that this framework evolved through analysis of the theoretical literature and extended and validated through testing and modification in the empirical contexts of real online learning experiences, in a similar way as the well-known Community of Inquiry (COI) evolved (Garrison, Anderson, \& Archer 2000). We hope that our Framework can be used to guide both research and practice in connectivist based learning courses in a similar way in which the COI has been used with social constructivist online learning courses.

\section{Acknowledgements}

We thank Dr.George Siemens for permission to access the data in Change 11 MOOC.

Our work is supported by a research project of the social science and humanities for young scholars by the Ministry of Education P.R. China-\#15YJC880093 and the Fundamental Research Funds for the Central Universities (JUSRP51418B,2015JDZD08).

\section{Statements on open data, ethics and conflict of interest}

We accessed all data from the blog, twitter, daily RSS aggregator and web sites associated with the Change 11 Massive Open Online Courses. All of this data is still available to other researchers. The majority of the data was aggregated to create a daily course newsletter which is an open access database accessible at: http://change.mooc.ca/cgi-bin/archive.cgi?page=newsletter.htm.

This research was carried out under ethical guidelines. We obtained permission from one of course facilitators- George Siemens to use the data in the research. When participants registered in the Change $11 \mathrm{MOOC}$, they signed an agreement that permitted use of their data in research (http://change.mooc.ca/privacy.htm). And all this data is open on the internet and can be accessed without passwords.

No conflict of interest exits in the submission of this manuscript, and the manuscript is approved by all authors for publication. I would like to declare on behalf of all the co-authors that the work described is original research that has not been published previously, and not under consideration for publication elsewhere, in whole or in part.

\section{References}

Anderson, T. \& Dron, J. (2011). Three generations of distance education pedagogy. The International Review of Research in Open and Distance Learning, 12, 3, 80-97.

Anderson, L. W., Krathwohl, D. R., Airasian, P. W., Cruikshank, K. A., Mayer, R. E., Pintrich, P. R., et al. (2000). A taxonomy for learning, teaching, and assessing: A revision of bloom's taxonomy of educational objectives. New York, NY: Pearson, Allyn \& Bacon. 
Arnold, P., Kumar, S., Thillosen, A. \& Ebner, M. (2014) Offering cMOOCs collaboratively: the COER13 experience from the convenor's perspective. In Cress, U. \& Kloos, C. D. (Eds.), Proceedings of the European MOOC Stakeholder Summit, 2014 (pp. 184-188).

Bi, J. J. \& Yang, X. M. (2014). Constructing personal learning space in the view of connectivism. Chinese Educational Technology, 8, 48-54.

Change 11 MOOC (2011). About this course [online]. Retrieved April 4, 2015, from http://change.mooc. ca/about.htm

Chen, L. (2004a). A hierarchical model for student and teacher interaction in distance learning. Distance Education in China, (05), 24-28 + 78 .

Chen, L. (2004b). A meta-analysis of the research on interactivity in distance teaching. Chinese Distance Education, 1, 13-20+78.

Conrad, D. (2014). Interaction and communication in online learning communities: toward an engaged and flexible future. In O. Zawacki-Richter and T. Anderson (Eds.), Online distance education: Towards a research agenda (pp. 381-402). Edmonton, AB: Athabasca University Press.

Downes, S. (2012a). Massively open online courses are 'here to stay' [online]. Retrieved April 4, 2015, from http://www.downes.ca/post/58676

Downes, S. (2012b). Connectivism and connective knowledge: Essays on meaning and learning networks. National Research Council Canada, [online]. Retrieved April 4, 2015, from http://www.downes.Ca/files/ books/Connective_Knowledge-19May2012.pdf

Dron, J. \& Anderson, T. (2014). Teaching crowds: Learning and social media. Edmonton, Canada: Athabasca University Press.

Elo, S. \& Kyngäs, H. (2008). The qualitative content analysis process. Journal of Advanced Nursing, 62, 1, $107-115$.

Fenwick, T. \& Edwards, R. (2011). Introduction: reclaiming and renewing actor network theory for educational research. Educational Philosophy and Theory, 43, s1, 1-14.

Fini, A. (2009). The technological dimension of a massive open online course: the case of the CCK08 course tools. The International Review of Research in Open and Distance Learning, 10, 5 [online]. Retrieved May 10, 2015, from http://www.irrodl.org/index.php/irrodl/article/viewArticle/643/ 1402Continued

Fournier, H., Kop, R. \& Durand, G. (2014). Challenges to research in MOOCs. MERLOT Journal of Online Learning and Teaching, 10, 1, 1-15.

Garcia, E., Elbeltagi, I., Brown, M. \& Dungay, K. (2014). The implications of a connectivist learning blog model and the changing role of teaching and learning. British Journal of Educational Technology, 26, $1-18$.

Garrison, D. R., Anderson, T., \& Archer, W. (2000). Critical inquiry in a text-based environment: computer conferencing in higher education. The Internet and Higher Education, 2, 2, 87-105.

Garrison, D. R., Anderson, T. \& Archer, W. (2001). Critical thinking, cognitive presence, and computer conferencing in distance education. American Journal of Distance Education, 15, 1, 7-23.

Gunawardena, C. N., Lowe, C. A. \& Anderson, T. (1997). Analysis of a global online debate and the development of an interaction analysis model for examining social construction of knowledge in computer conferencing. Journal of Educational Computing Research, 17, 4, 397-431.

Henri, F. (1992). Computer conferencing and content analysis. In A. Kaye (Ed.), Collaborative learning through computer conferencing: The Najaden papers (pp. 117-136). Berlin: Springer-Verlag.

Kop, R. \& Carroll, F. (2011). Cloud computing and creativity: learning on a massive open online course. European Journal of Open, Distance and E-learning [online]. Retrieved May 11, 2015, from http://www. eurodl.org/materials/special/2011/Kopp_Carroll.htm

Laurillard, D. (2000). Rethinking university teaching: A conversational framework for the effective use of learning technologies (2nd ed.). London: Routledge.

Levy, D. (2011). Lessons learned from participating in a connectivist massive online open course (MOOC). In Proceedings of the Chais conference on instructional technologies research 2011: Learning in the technological era, pp. 31-36.

Milligan, C., Littlejohn, A. \& Margaryan, A. (2013). Patterns of engagement in connectivist MOOCs. Journal of Online Learning \& Teaching, 9(2) [online]. Retrieved May 10, 2015, from http://jolt.merlot.org/ vol9no2/milligan_0613.htm 
Rodriguez, C. O. (2013). Two distinct course formats in the delivery of connectivist MOOCs. Turkish Online Journal of Distance Education, 14, 2, 66-80.

Rourke, L., Anderson, T., Garrison, D. R., \& Archer, W. (2001). Methodological issues in the content analysis of computer conference transcripts. International Journal of Artificial Intelligence in Education (IJAIED), $12,8-22$.

Saadatmand, M. \& Kumpulainen, K. (2014). Participants' perceptions of learning and networking in connectivist MOOCS. MERLOT Journal of Online Learning and Teaching, 10, 1, 16-30.

Sharma, P., Land, S. M., Jordan, R., Swain, J. \& Smith, B. K. (2010). Patterns of interaction and everyday knowledge sharing in social network environments. In: Proceedings of the 9th International Conference of the Learning Sciences-Volume 2, International Society of the Learning Sciences (pp. 394-396).

Siemens, G. (2005a). Connectivism: a learning theory for the digital age. International Journal of Instructional Technology and Distance Learning, 2, 1, 3-10.

Siemens, G. (2005b). Connectivism: Learning as network-creation [online]. Retrieved May 10, 2015, from http://www.elearnspace.org/Articles/networks.htm

Siemens, G. (2011). Orientation: Sensemaking and wayfinding in complex distributed online information environments (Doctoral dissertation, University of Aberdeen).

Siemens, G. (2012). MOOCs are really a platform. eLearnspace [online]. Retrieved May 10, 2015, from http://www.elearnspace.org/blog/2012/07/25/moocs-are-really-a-platform/

Siemens, G. (2013). Massive Open Online Courses: Innovation in Education?[online]. Retrieved May 10, 2015, from https://oerknowledgecloud.org/sites/oerknowledgecloud.org/files/pub_PS_OER-IRP_CH1. pdf

Smith, B. \& Eng, M. (2013). MOOCs: A learning journey. Hybrid Learning and Continuing Education (pp. 244 255). Berlin, Heidelberg: Springer.

Wang, Z. L. (2011). Connectivism and new constructivism: form connection to innovation. Journal of Distance Education, 5, 34-40.

Wang, Z.J. \& Chen, L. (2015). Theory framework building of instructional interaction in connectivist learning context. The Journal of Open Educational Research, 5, 25-34.

Wang, Z.J., Chen, L. \& Zhen, Q. (2014). The development track of MOOCs and three forms of practice. China Educational Technology, 7, 25-33.

Wang, Z.J., Chen, L. \& Anderson, T. (2014). A framework for interaction and cognitive engagement in connectivist learning contexts. The International Review of Research in Open and Distributed Learning. 15, 2, 121-141.

Yuan, L., Powell, S. \& Cetis, J. MOOCs and open education: Implications for higher education a white paper [online]. Retrieved May 10, 2015, from https://www.oerknowledgecloud.org/sites/oerknowledgecloud. org/files/MOOCs-and-Open-Education.pdf 